Bull. Mater. Sci., Vol. 16, No. 6, December 1993, pp. 405-431. (C) Printed in India.

\author{
The 1993 Distinguished \\ Materials Scientist Lecture
}

\author{
The Materials Research Society \\ of India
}

\title{
Four decades of research in solid state chemistry*
}

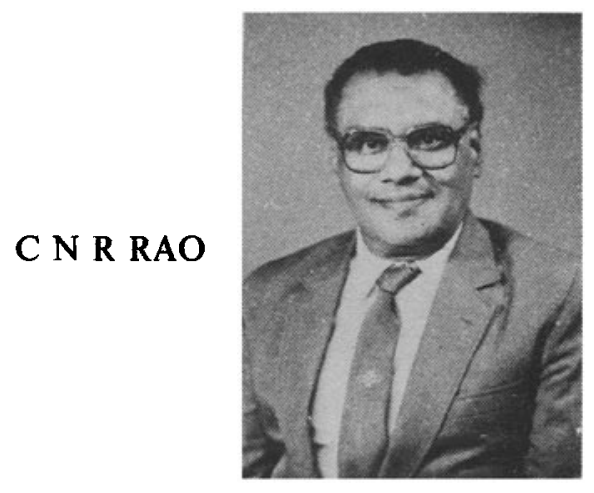

Solid State and Structural Chemistry Unit and CSIR Centre of Excellence in Chemistry, Indian Institute of Science, Bangalore 560012, India

and

Jawaharlal Nehru Centre for Advanced Scientific Research, Bangalore 560012, India

\begin{abstract}
*Distinguished Materials Scientist Award Lecture presented at the MRSI meeting, Trivandrum on February 9, 1993.

Professor C N R Rao, born on June 30, 1934 in Bangalore, received the M. Sc. degree in Physical Chemistry from Banaras Hindu University in 1953, the Ph.D degree from Purdue University, USA in 1958 and the D.Sc. degree from the University of Mysore in 1960. He was a research scholar at IIT, Kharagpur (1953-54), Lecturer at the Indian Institute of Science (1959-63), Associate Professor (1963-64) and Professor (1964-76) at the Indian Institute of Technology, Kanpur. He was the first Head of the Chemistry Department as well as the first Dean of Research at IIT, Kanpur. He moved back to the Indian Institute of Science in 1976 where he was founder Chairman of the Solid State and Structural Chemistry Unit and the Materials Research Laboratory till 1984, when he became the Director of the Institute. He has been President of the Jawaharlal Nehru Centre for Advanced Scientific Research, Bangalore since its founding in 1989. He was President of the Indian National Science Academy and the Indian Academy of Sciences as well as the International Union of Pure and Applied Chemistry. He was Commonwealth Professor at the University of Oxford and Nehru Professor at the University of Cambridge. He is the author of over 800 research papers and has authored/edited 30 books pertaining to solid state chemistry, spectroscopy, molecular structure, surface science and chemical education. He is a member of the editorial boards of over 15 international journals and is the founder-editor of the Bulletin of Materials Science. He is Honorary
\end{abstract}


Professor at the University of Wales, Cardiff (UK) and Adjunct Professor at the Pennsylvania State University.

Of the many honours received by Professor Rao, mention may be made of the Marlow Medal of the Faraday Society, London (1967), Bhatnagar Prize (1968), Jawaharlal Nehru Fellowship (1973), Padma Shri (1974), Sir C V Raman Award of the University Grants Commission (1975), Centennial Foreign Fellowship of the American Chemical'Society (1976), Federation of the Indian Chambers of Commerce and Industry Prize (1977), S N Bose Medal of the Indian National Science Academy (1980), Royal Society of Chemistry (London) Medal (1981), P C Ray Medal of the Indian Chemical Society (1984), Padma Vibhushan (1985), Nehru Award for Science (1988), Modi Award for innovative science (1989), Hevrovsky Gold Medal of the Czechoslovak Academy (1989), Honorary Fellowship of the Royal Society of Chemistry, London (1989), Meghnad Saha Medal of INSA (1990), CSIR Golden Jubilee Prize in physical sciences (1991), Blackett Lectureship of the Royal Society (1991), K K Barooah Foundation Award for Science (1992) and Goyal Prize in Chemistry (1993).

Professor Rao is a Fellow of the Science Academies in India and of the Royal Society, London. He is a Foreign Associate of the US National Academy of Sciences and a Foreign Member of the American Academy of Science and Arts, the Russian Academy of Science as well as the Czech, Polish, Serbian and Slovenian Science Academies. He is a member of the Pontifical Academy of Sciences and a founder fellow of Third World Academy of Sciences (of which he is now Vice President). He is an honorary member of the Materials Research Societies of Japan and South Korea and of the International Academy of Ceramics and honorary fellow of Institution of Engineers and IETE. He has received D.Sc. (honoris Causa) from 22 Universities. He was a member of the first National Committee on Science and Technology and later of the Scientific Advisory Committee to the Union Cabinet. He was Chairman of the Science Advisory Council to Prime Minister Rajiv Gandhi.

\begin{abstract}
Solid state chemistry was in its infancy when the author got interested in the subject. In this article, the author outlines the manner in which the subject has grown over the last four decades, citing representative examples from his own contributions to the different facets of the subject. The various aspects covered include synthesis, structure, defects, phase transitions, transition metal oxides, catalysts, superconductors, metal clusters and fullerenes. In an effort to demonstrate the breadth and vitality of the subject, the author shares his own experiences and aspirations and gives expression to the agony and ecstacy in carrying out experimental research in such a frontier area in India.
\end{abstract}

Keywords. Solid state chemistry; fullerenes; transition metal oxides; perovskites; phase transition.

\title{
1. Prologue
}

I have been working in the area of solid state chemistry for nearly four decades. When I first got seriously interested in the subject in the early 1950's it was still in its infancy. Very few chemists, let alone others, recognized solid state chemistry as an integral part of main-stream chemistry. In spite of such benign tolerance, solid state chemistry has gradually emerged to become a crucial component of modern solid state and materials science (figure 1). Let me quote from the prefaces of two books published in 1970 and 1986 (Rao 1970; Rao and Gopalakrishnan 1986) to show the remarkable change in the scenario. The preface of the book, "Modern aspects of solid state chemistry" published in 1970 states:

"The three natural streams of present-day chemistry are structure, dynamics and synthesis and all these three elements are essential for the study of materials, particularly in the solid state. The solid state provides challenging opportunities for illustrating and applying principles of chemistry to 


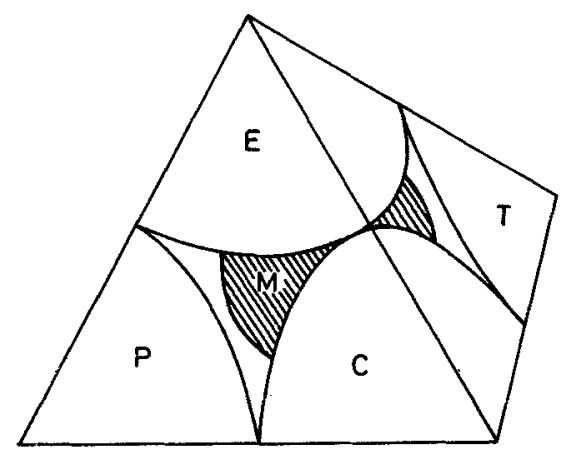

Figure 1. Materials Science (M) at the centre of a tetrahedron: P, Physics, C, Chemistry, T, Theory, E, Engineering (modified from Goodenough and Rao 1983).

systems of academic interest and technological importance. There are several practising solid state chemists in universities and research laboratories, but the subject has not yet become part of the formal training programme in chemistry. Being one of the new frontiers of chemistry, solid state chemistry has a tremendous future and undoubtedly demands the active involvement of many more chemists."

Contrast this with the first paragraph in the Preface of the book "New directions in solid state chemistry" published in 1986:

"Although solid state science is an area of intense research activity pursued by physicists and materials scientists, the contributions of chemists to this area have a distinct identity. The great skill of chemists in developing novel methods for the synthesis of complex materials, and their understanding of the intricacies of structure and bonding, make their contributions to solid state science unique. At the present time, solid state chemistry is mainly concerned with the development of new methods of synthesis, new ways of identifying and characterizing materials and of describing their structure and above all, with new strategies of tailor-making materials with desired and controllable properties, be they electronic, magnetic, dielectric, optical, adsorptive or catalytic. It is heartening that solid state chemistry is increasingly coming to be recognized as an emerging area of chemical science".

Clearly, solid state chemistry has come of age. It has been a pleasure to see the subject grow. In this process, I have tried to contribute to the various facets of the subject which include synthesis, structure, phase transitions, defects, properties and phenomena. A large part of my work relates to transition metal oxides including superconductors, although in recent years, other novel solids have equally absorbed my attention.

\section{Early beginnings}

I started to pursue research towards a Ph.D degree in 1953, soon after obtaining a Master's degree in physical chemistry (with a thesis in partial fulfilment of the degree) 
from the Banaras Hindu University. At that time, I had the opportunity to talk to some research students at the Indian Institute of Science and at the Indian Institute of Technology, Kharagpur, who were working on oxide catalysts. Some of them were carrying out thermal analysis of these oxides. I was puzzled as to how the structure and solid state properties of oxides were related to their catalytic activity. I myself was working on the surface properties of supported metal catalysts. After completing nearly a year as a research scholar, I got the feeling that I would not have a sound knowledge of physical chemistry (of that time), even though I may get a Ph.D. degree based on a thesis on surface chemistry and catalysis. I did not understand many of the papers published in journals such as the Journal of Chemical Physics and the Journal of the American Chemical Society. At that time, I had read the famous book by Linus Pauling on the "Nature of the chemical bond" and was much inspired by the structural approach to chemistry expounded in the book. With the advice of some friends and teachers, I decided to go to the Purdue University towards the end of 1954 to pursue my Ph.D. studies, the main motivation being that I could take a variety of courses in chemistry and physics as part of the Ph.D. programme. I took up the chemical physics programme with physical chemistry (major) and physics (minor), but I had to pass many examinations in other branches of chemistry as well. The courses in physics included solid state physics, experimental measurements on solids and crystallography.

For my Ph.D thesis at Purdue, I took up the study of molecular structure by electron diffraction of gases (with Professor R L Livingston). During my first year, I carried out spectroscopic and other physico-chemical studies of organic molecules as a research assistant to Prof. Eugene Lieber. In my spare time, I worked with a few other Professors in the Purdue Chemistry Department on structural problems of interest to them. I fully made use of the X-ray diffraction facilities of the Purdue Physics Department for which I had free access. Prof. Herbert Brown was a great source of inspiration and with his guidance, I published some papers relating spectroscopic properties of molecules with reactivity. At the end of three years, I obtained the Ph.D. degree (I was 23.5 years old by then). The thesis involved the determination of structures of several interesting gaseous molecules by the rotating sector electron diffraction method which was new at that time. We had to fabricate a new instrument, including the rotating sectors. Thanks to Prof. Livingston, I collaborated with almost all the students in the laboratory in solving molecular structures and also continued my association with Prof. Lieber who had then moved to Chicago. It was around this time that my friend Al Czanderna, who was working on the surface properties of spectroscopically pure $\mathrm{TiO}_{2}$ with George Honig, asked me to determine the structure of his $\mathrm{TiO}_{2}$ sample by $\mathrm{X}$-ray diffraction. I found that it had the anatase structure. Soon we thought that we should study the kinetics of transformation of pure anatase to the rutile form. We published a paper in the Transactions of the Faraday Society on this topic (Czanderna et al 1958). Before leaving Purdue, I was a post-doctoral fellow and instructor for a short period. I also submitted my thesis for the D.Sc. degree of the University of Mysore based on my papers (other than those covering my Ph.D. work) in 1958.

Around the middle of 1958 , I went to the University of California, Berkeley, for post-doctoral work with Professor Kenneth Pitzer. The Chemistry Department at Berkeley was most exciting with outstanding persons like Pitzer, Seaborg, Calvin, Giaque and others. The influence of $\mathrm{G} N$ Lewis could be felt everywhere. I got to 
know young George Pimentel at that time whom I used to meet regularly. For my post-doctoral work, I studied the thermal properties of $\mathrm{Ag}_{2} \mathrm{O}$ and some disordered oxides (Rao and Pitzer 1960; Pitzer et al 1961), besides carrying out NMR and other studies on molecules. I collaborated with some others to study the phase transitions and other aspects of complex solids (see for example, Rao and Gregor 1959). Towards the end of 1959 , I decided to come back to India. It was then that I came across a book on solid state chemistry edited by Garner which dealt with the decomposition of solids, nucleation phenomena and so on. I was also aware of the work of Carl Wagner in Germany and J S Anderson in Britain who had done outstanding work on defects in ionic solids. I thought that when I went back to India, I should start some work on the chemistry of solids since this would give me a possibility of working in a relatively new area.

\section{Start of professional career}

I joined the Inorganic and Physical Chemistry Department of the Indian Institute of Science as a Lecturer late in 1959. I was just over 25 years old at that time. The Institute had no X-ray diffractometer or a proper IR or UV spectrometer. I thought of a few problems in spectroscopy which could be done with a simple manual UV spectrophotometer. I depended on other laboratories to record infrared spectra. Some of the spectroscopic work done without spectrometers between 1959-1961 by my students have become citation classics. During this period, I wrote two books on spectroscopy (Rao 1961a, 1963), the book on UV-visible spectroscopy being the first one to introduce molecular-orbital description of electronic transitions. I got to know Professor C V Raman who was extraordinarily good to me (He has been a source of great inspiration in my professional life). I started a modest programme in solid state chemistry, making use of a tiny powder X-ray diffraction camera $(5.73 \mathrm{~cm}$ dia) available in the department. My first research student in solid state chemistry, Yoganarasimhan, worked on the transformations of both the anatase and brookite forms of $\mathrm{TiO}_{2}$ to the rutile form (figure 2) and examined the factors affecting the phase transitions such as particle size and impurities (Rao 1961b; Rao et al 1961; Yoganarasimhan and Rao 1962). He also studied disordered oxides obtained by the decomposition of solids.

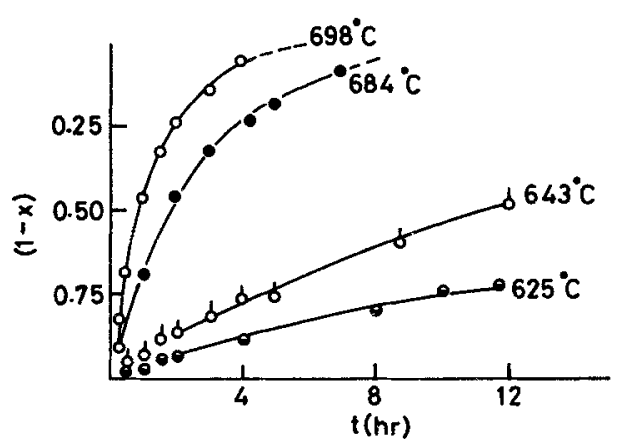

Figure 2. Kinetics of transformation of spectroscopically pure $\mathrm{TiO}_{2}$ (anatase to rutile) (Rao 1961b). 
I shifted to the Indian Institute of Technology (IIT), Kanpur, early in 1963 as an Associate Professor (Professor in 1964) in the new Chemistry Department. The main reason for leaving the Indian Institute of Science, Bangalore, at that time was that it did not have adequate facilities for research in solid state and structural chemistry. IIT Kanpur, which was just coming up with American aid, promised much. It became a great centre of academic activity and gave me tremendous opportunity to build a new chemistry department as its first Head. If IIT Kanpur did not have me in 1963, I would have left the country to join the faculty of an American university. At IIT Kanpur, I tried to develop research programmes both in solid state chemistry and chemical spectroscopy; I will restrict myself to the first subject here.

Around 1964, I thought that I should initiate research on defects in ionic solids and on the problem of non-stoichiometry. It is nice to recall that a fundamental enigma from the beginning of chemistry was whether to consider chemical compounds to be stoichiometric or nonstoichiometric. Even as late as 1965 , a compound such as $\operatorname{Pr}_{6} \mathrm{O}_{11}$ was considered to be nonstoichiometric. I wanted to know what it meant. It was found at that time that these oxides could be expressed as members of the homologous series, $\mathrm{Ln}_{n} \mathrm{O}_{2 n-2}$. If so, how could they be non-stoichiometric? We did some work on the oxidation of $\operatorname{Pr}_{2} \mathrm{O}_{3}$ to $\operatorname{Pr}_{6} \mathrm{O}_{11}$ (Ramdas et al 1970). We examined phase diagrams of such oxides. We could treat $\operatorname{Pr}_{6} \mathrm{O}_{11}$ with dilute acid and obtain pure $\mathrm{PrO}_{2}$ in the fluorite structure (Sastry et al 1966). Such work did tell us something about the nature of these rare earth oxides and indicated that $\operatorname{Pr}_{6} \mathrm{O}_{11}$ was not nonstoichiometric as people understood it at that time. We measured electrical properties of these oxides and showed how the conductivity was proportional to the product of the concentrations of the trivalent and the tetravalent metal species, the conductivity becoming maximum (and thermopower, near zero) when the two species were in equal proportion (Chandrashekhar et al 1967). We also carried out measurements on defects in ionic solids at Kanpur.

I continued the study of the phase transitions in several inorganic solids such as metal halides, nitrates, sulphates and oxides. We tried to understand the nature of hysteresis in phase transitions and employed the Born model of ionic solids to understand phase transitions in alkali halides (Rao K J and Rao C N R 1966; Rao K J et al 1967).

We started some work on the electrical properties of metal complexes and chargetransfer compounds (Bhat et al 1967; Bhat and Rao 1969; Rao and Bhat 1969), but soon abandoned it since there was no way of preparing or procuring high purity crystals of such materials.

My resolve to continue in solid state chemistry got further reinforced by my election to the Fellowship of the Indian Academy of Sciences (1965) due to the personal interest of Prof. Raman and by the award of the Marlow Medal (1967) by the Faraday Society, England, for contributions to solid state chemistry and spectroscopy. These early recognitions have meant much to me.

\section{Defects in inorganic solids}

The theory of creation, interaction and migration of defects in ionic solids such as alkali halides and silver halides had aroused much interest in me (Rao K J and Rao C N R 1968; Ramdas et al 1973; Shukla et al 1973a, b; Ramdas and Rao 1976). We continued such work till 1976, improving on the methodology and the level of 
sophistication. The work involved extensive computation which was difficult to do in Kanpur. We used the computers at TIFR and at IIT Madras to carry out state-ofthe-art calculations employing the shell model, novel potentials etc. (see for example, Beniere et al 1977, Uppal et al 1978). While I continued to work in this area, it was becoming clear in the late 1960 s that point defects themselves had no real significance in much of the solid state chemistry of oxides. It seemed that when a sufficient concentration of point defects was present, there was a tendency for solids to eliminate them. Nature did not appear to tolerate high concentrations of point defects (this has since been established). While physicists may be interested in very small concentrations of point defects in ionic solids, I thought that it was not a very important problem since I was mainly interested in transition metal oxides. One had to study the structural aspects involved in the elimination of point defects in metal oxides in order to explain nonstoichiometry. Ideas such as crystallographic shear introduced by Magneli, Wadsley, Anderson and others were getting to be known. At this time, I got to personally meet Prof. J S Anderson (although he had examined the Ph.D. theses of some of my students earlier). He visited IIT Kanpur to lecture at the first winter school in solid state chemistry in 1969 (Prof. J M Honig was the other lecturer). It was at this meeting that Prof. Anderson enunciated the nature of defects in oxide systems and the mechanism of elimination of point defects. This may be found in the Proceedings of the Winter School entitled "Modern aspects of solid state chemistry" (Rao 1970).

\section{Transition metal oxides}

I started some work on transition metal oxides around 1965. Transition metal oxides can be metallic (e.g. TiO, VO) or insulating (e.g. $\mathrm{TiO}_{2}, \mathrm{~V}_{2} \mathrm{O}_{5}$ ). There are oxides which show metal to non-metal transitions (e.g. $\mathrm{V}_{2} \mathrm{O}_{3}, \mathrm{Ti}_{2} \mathrm{O}_{3}$ ). There are ferromagnetic oxides (e.g. $\mathrm{CrO}_{2}$ ) and antiferromagnetic ones (e.g. $\mathrm{MnO}$, $\mathrm{NiO}$ ). $\mathrm{My}$ interest in these oxides got considerably strengthened by a Visiting Professorship at Purdue University during 1967-68. During this period I worked closely with Prof. J M Honig and his group. Our collaboration and friendship have continued over the years and we still work jointly on some problems of mutual interest (see for example, Rao et al 1984a, Buttrey et al 1988). Of the many problems related to binary transition metal oxides, I recall with pleasure, some of the early studies of metal-insulator transitions in $\mathrm{Ti}_{2} \mathrm{O}_{3}, \mathrm{Ti}_{3} \mathrm{O}_{5}, \mathrm{VO}_{2}, \mathrm{NbO}_{2}$ and related systems (see for example, Rao et al 1968, 1971, 1973; Cheetham and Rao 1976). I started a programme on the study of perovskite oxides with G V Subba Rao around 1966. We wrote the first review on transition metal oxides in 1970 and a monograph on the subject published by the National Bureau of Standards (Rao and Subba Rao 1970, 1974). In 1971, we had the second winter school in solid state chemistry with Prof. J B Goodenough and Prof. L Eyring as guest lecturers. Transition metal oxides was the main topic in this school (Rao 1974). The area of transition metal oxides has been one of my main preoccupations ever since 1965. References to much of the work from this laboratory in this area may be found in an article in the Annual Reviews of Physical Chemistry (Rao 1989).

\section{Oxford experience}

In 1973, I received an invitation to be Commonwealth Visiting Professor in the Inorganic Chemistry Laboratory at the University of Oxford. This was an active 
school in solid state chemistry headed by Prof. J S Anderson. It was here that I got directly involved in the study of ultramicro-structures of solids by high resolution electron microscopy (HREM). I also studied the electronic structures of oxides by employing X-ray photoelectron spectroscopy (ESCA). HREM investigations included many interesting oxides such as the Aurivillus family of oxides, perovskite polytypes and silicon carbide (Gai et al 1975, 1976; Hutchison et al 1976). When I came back from Oxford to IIT Kanpur, it was clear that I required much better characterization and measurement facilities to carry out meaningful research in solid state chemistry.

\section{Shift to Bangalore in search of better facilities}

Modern solid state chemistry research involves the synthesis or design of novel solids, their characterization and structural elucidation, followed by a study of the properties of significance (Honig and Rao 1981). A 'complete' solid state chemist has to be quite versatile and should have at his disposal many sophisticated tools. The situation in my laboratory at Kanpur was unfortunately far from satisfactory and it did not appear possible to build the necessary infrastructure to make a new beginning. I needed good X-ray diffraction facilities for crystal structure determination and a high resolution electron microscope for the study of ultramicro-structure. A photoelectron spectrometer was necessary for the study of electronic-structure $I$ decided to leave Kanpur with much sadness. I was seriously considering offers from the US, but in the meantime got an opportunity to build a new department devoted to solid state chemistry and also a new Materials Research Laboratory at the Indian Institute of Science. I came back to the Institute in Bangalore in 1976. Since then, we have gradually acquired many facilities. To start with, we ensured that we could measure all the properties down to liquid helium temperatures. We got a routine powder $\mathrm{X}$-ray diffractometer and an ESR spectrometer in 1978. Around 1980, we could get a highresolution electron microscope for lattice imaging. We have used electron microscopy for the study of a variety of oxides, thanks to G N Subbanna and L Ganapathi (figure 3). Early in 1978, I could establish a surface science laboratory with a good photoelectron spectrometer. Late in the 1980 s, we got a solid state NMR spectrometer.

\section{Perovskites}

Let me briefly present here the kind of problems that we have pursued with perovskites. The reason we wanted to work on perovskites is because the structure is ideal for $180^{\circ}$ cation-anion-cation interaction and there is no cation-cation interaction (figure 4). One can vary the covalency (or the interaction between the metal and oxygen orbitals) in this structure by varying the central cation or/and the transition metal-ion and obtain a wide variation in properties. We examined the electronic and magnetic properties of entire families of perovskites of the type $\mathrm{LnMO}_{3}$ ( $\mathrm{Ln}$, rare earth or $\mathrm{Y}$; $\mathrm{M}$, first-row transition metal):

$$
\mathrm{LnTiO}_{3}, \mathrm{LnVO}_{3}, \mathrm{LnCrO}_{3}, \mathrm{LnMnO}_{3}, \mathrm{LnFeO}_{3}, \mathrm{LnCoO}_{3}, \mathrm{LnNiO}_{3} .
$$

Of these, the titanates and nickelates possessing low-spin trivalent transition metal ions are metallic. On the other hand, $\mathrm{LnCrO}_{3}, \mathrm{LnMnO}_{3}$ and $\mathrm{LnFeO}_{3}$ are antiferromagnetic insulators (Subba Rao et al 1970, 1971; Ganguly et al 1976). $\mathrm{LaCoO}_{3}$ and 


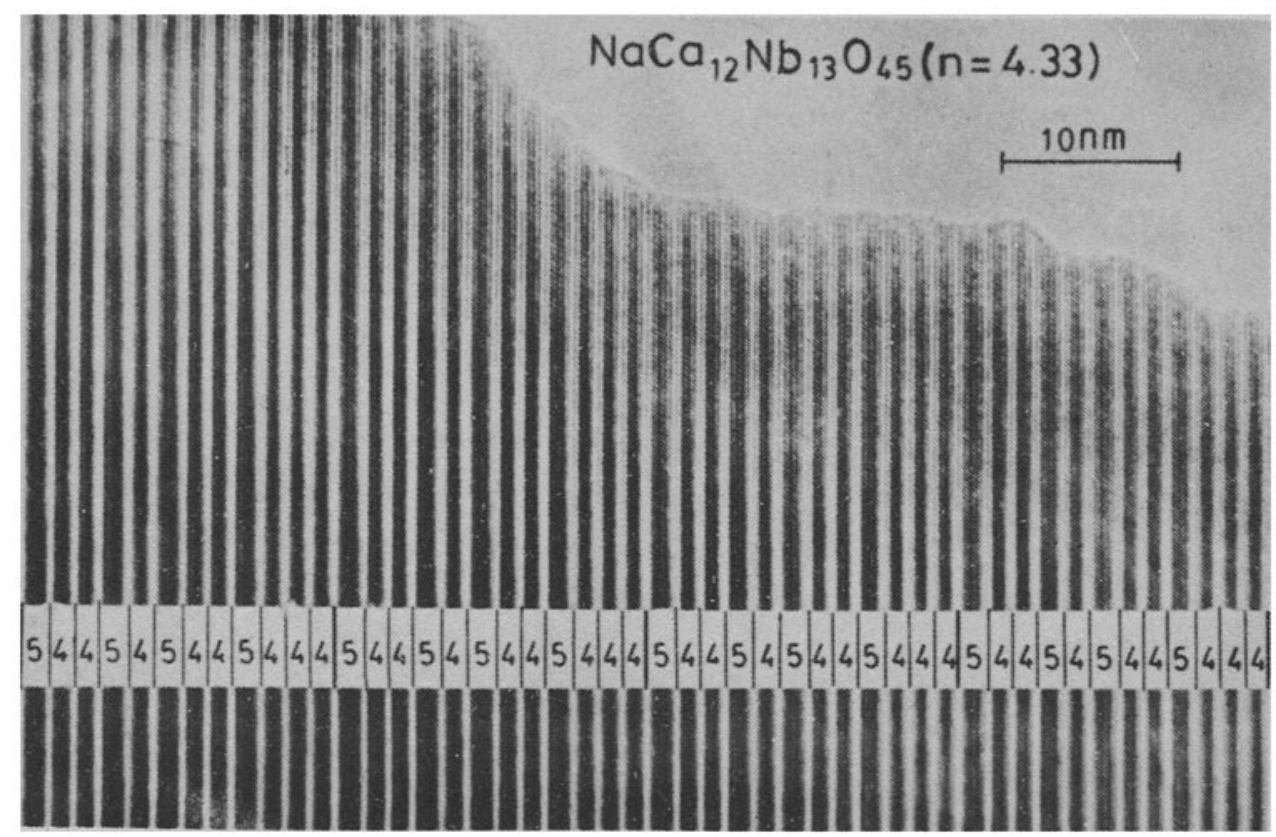

Figure 3. Lattice image of the $n=4 \cdot 33$ member in the $A_{n-1} B_{n} O_{3 n+2}$ family with the sequence 544545445444 unit of $176 \mathrm{~A}$ (from Ganapathi).

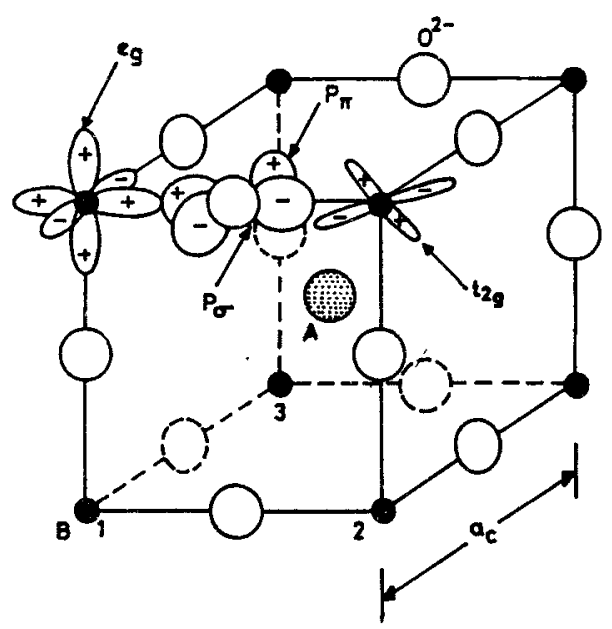

Figure 4. Perovskite structure showing cation-anion-cation interaction along the edge.

other cobaltates are specially interesting, in that $\mathrm{Co}^{3+}$ can be in the low-spin $\left(t_{2 q}^{6}\right)$ or the high-spin $\left(t_{2 g}^{4} e_{g}^{2}\right)$ state. While at low temperatures, $\mathrm{LaCoO}_{3}$ is a diamagnetic insulator, with increase in temperature, the high-spin population increases eventually resulting in a phase transition due to the ordering of the two spin states. At high temperatures $(>1200 \mathrm{~K}$ ), the material becomes metallic resulting from the electrontransfer between different spin/oxidation states of cobalt (Bhide et al 1972; Jadhao 

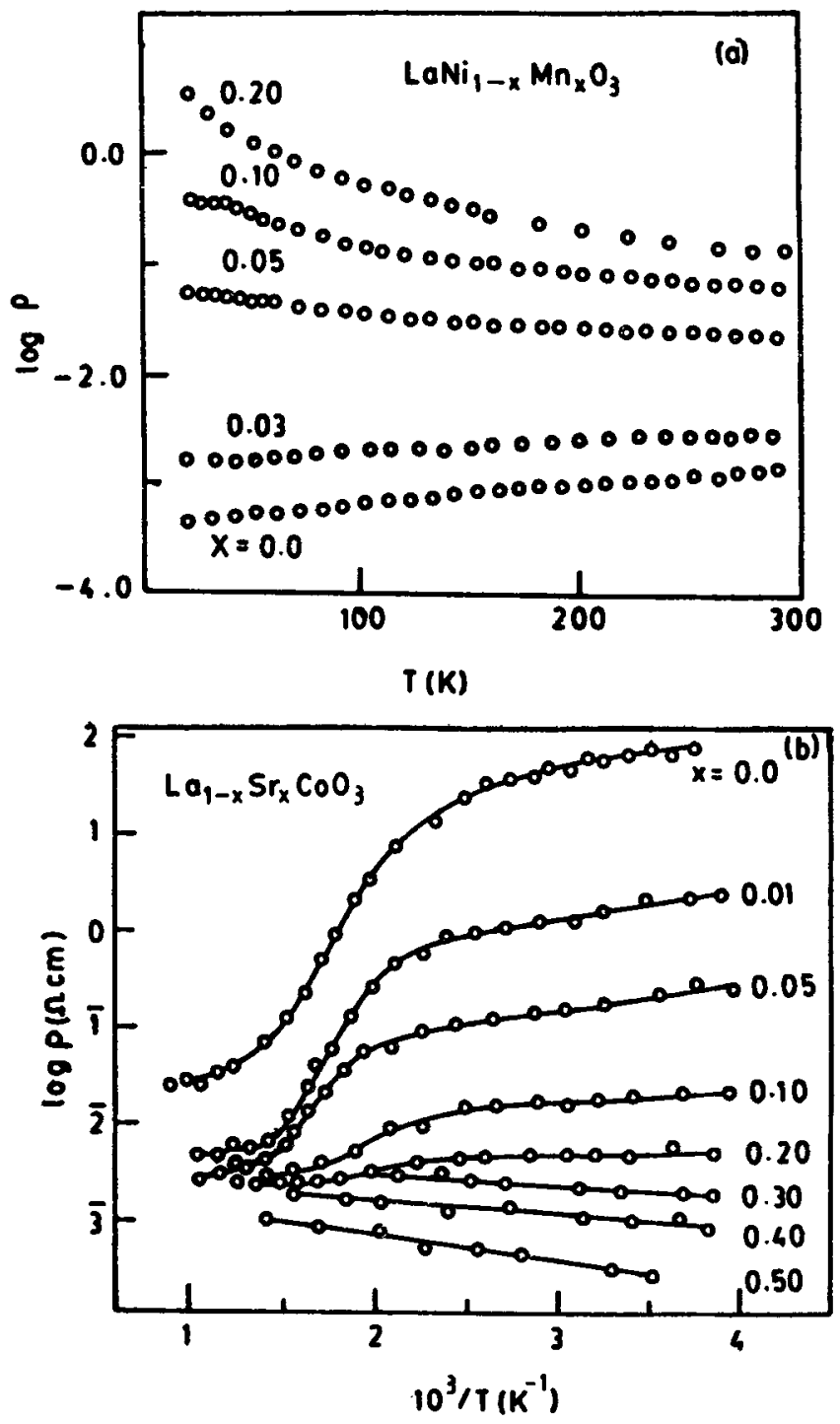

Figure 5. Resistivity data of (a) $\mathrm{LaNi}_{1-x} \mathrm{Mn}_{x} \mathrm{O}_{3}$ and (b) $\mathrm{La}_{1-x} \mathrm{Sr}_{x} \mathrm{CoO}_{3}$ showing composition-controlled metal insulator transitions (from Rao 1986b).

et al 1976). Doping $\mathrm{LnCoO}_{3}$ by a divalent ion such as $\mathrm{Sr}^{2+}$ or $\mathrm{Ba}^{2+}$, as in $\mathrm{Ln}_{1-x} \mathrm{Sr}_{x} \mathrm{CoO}_{3}$, progressively renders it metallic and ferromagnetic due to the fast electron transfer between the $\mathrm{Co}^{3+}$ and $\mathrm{Co}^{4+}$ states (Rao et al 1977; Bahadur et al 1979). We have investigated these cobaltates by a variety of methods including ${ }^{57} \mathrm{Co}$ Mössbauer spectroscopy, ferromagnetic resonance, photoemission spectroscopy and EXAFS. Electron transport properties of $\mathrm{LnCoO}_{3}$ doped lightly by $\mathrm{Sr}^{2+}$ and other similar oxide systems can be understood in terms of variable range hopping as in disordered systems (Om Parkash and Rao 1977). While working on these oxides, I 
got into correspondence with Sir Nevill Mott. Later, when I was in Oxford and Cambridge, I got to know him well which resulted in frequent meetings and joint publications (see for example, Rao and Mott 1975). I had the pleasure of editing a festschrift volume for the 80th birthday of Prof. Mott (Edwards and Rao 1985).

The metal-nonmetal transition in $\mathrm{Ln}_{1-x} \mathrm{Sr}_{x} \mathrm{CoO}_{3}$ (see figure 5b) is a situation similar to impurity doping. Another system showing metal-nonmetal transitions is $\mathrm{LaNi}_{1-x} \mathrm{M}_{x} \mathrm{O}_{3}\left(\mathrm{M}=\mathrm{Mn}\right.$, Co etc), where $\mathrm{LaNiO}_{3}(x=0 \cdot 0)$ is metallic (see figure 5a for the Mn system). On increasing $x$, the material becomes an insulator) (Ganguly et al 1984). Interestingly, in all such systems, the coefficient of resistivity changes sign across an universal value of resistivity, corresponding to Mott's minimum metallic conductivity (Rao and Ganguly 1985). We have examined the effect of dimensionality on the electronic and magnetic properties (e.g. $\mathrm{LaNiO}_{3}, \mathrm{La}_{4} \mathrm{Ni}_{3} \mathrm{O}_{10}, \mathrm{La}_{3} \mathrm{Ni}_{2} \mathrm{O}_{7}$, $\mathrm{La}_{2} \mathrm{NiO}_{4}$ with decreasing dimensionality from 3 to 2; see for example, Rao et al 1988). We have discussed the defect chemistry of perovskites in some detail (Rao et al 1984b). Perovskites continue to interest me. Recently we have prepared $\mathrm{LaMnO}_{3+\delta}$ by different chemical routes in order to increase the $\mathrm{Mn}^{4+}$ content to $\sim 50 \%$, to render it cubic and ferromagnetic (Verelst et al 1993). We have worked on bismuth oxides of possessing different structures (Ramanan et al 1981, 1985; Varma et al 1990).

Around 1970, we started work on oxides of $\mathrm{K}_{2} \mathrm{NiF}_{4}$ structure at IIT, Kanpur and published our first paper on $\mathrm{La}_{2} \mathrm{CuO}_{4}$ and $\mathrm{La}_{2} \mathrm{NiO}_{4}$ in 1973 (Ganguly and Rao 1973). Later work at Bangalore showed that $\mathrm{Cu}$ in $\mathrm{Ln}_{2} \mathrm{CuO}_{4}$ had no magnetic moment and that $\mathrm{La}_{2} \mathrm{CuO}_{4}$ was antiferromagnetic (Ganguly et al 1980). Magnetic and electrical properties of $\mathrm{La}_{2} \mathrm{NiO}_{4}$, specially its oxygen excess non-stoichiometry were investigated (see for example, Buttrey et al 1988). Solid solutions of $\mathrm{La}_{2} \mathrm{CuO}_{4}(T)$ and $\mathrm{Nd}_{2} \mathrm{CuO}_{4}\left(T^{\prime}\right)$ were investigated as early as 1982 (Singh et al 1982). We wrote a overview on the structure and properties of two-dimensional oxides of $\mathrm{K}_{2} \mathrm{NiF}_{4}$ structure (Ganguly and Rao 1984). Little did we realize then that $\mathrm{La}_{2} \mathrm{CuO}_{4}$ was going to become famous because of high-temperature superconductivity. A severe problem we faced in our work at IIT Kanpur was the non-availability of liquid helium. We could measure properties only down to liquid nitrogen temperatures.

\section{Phase transitions}

The work on phase transitions has continued over the years. A variety of phase transitions of organic and inorganic solids have been studied by my students. We have employed infrared and Raman spectroscopy to study the phase transitions of a variety of molecular solids and many of these results are described in my EUCMOS plenary lecture (Rao 1993b). We have investigated various types of transitions (Rao 1984), including spin-state transitions (Madhusudan et al 1980; Mohan Ram et al 1983; Rao 1985b), glass transition (Parthasarathy et al 1983). I am not a theoretical chemist, but whenever the situation demanded or when a student was more inclined towards theoretical work, I have encouraged the effort and helped as much as I could. For example, Ramasesha and others carried out theoretical investigations of spin-state transitions and polytypism (Ramasesha et al 1979, Uppal et al 1980). In 1978, I wrote a monograph on "Phase transitions in solids" jointly with. K J Rao (Rao and Rao 1978). A few lines from the preface of this book would be of interest. 
"The subject of phase transitions is of vital interest to physicists, chemists, metallurgists, ceramists and others involved in the study of solids. This cross-disciplinary subject is not only of academic importance, but also of technological relevance. The literature abounds in experimental and theoretical studies of phase transitions in solids, and the subject is continually growing. Newer systems undergoing transitions and newer kinds of transitions are being constantly reported. At the same time, many unifying concepts have emerged in recent years which provide a better understanding of the nature of phase transitions. Although books and reviews devoted to specific aspects of phase transitions, like critical phenomena, ferroelectricity, soft modes, or metal-insulator transitions, have been appearing from time to time, most texts of solid state physics and chemistry deal with this subject cursorily. Metallurgists generally pay a lot more attention to this topic, but their treatment is by necessity confined to metals and alloys. Phase transitions, on the other hand, are of significance to a much wider spectrum of materials."

I started making use of computer simulation to study phase transitions around 1984 with Yashonath (Yashonath and Rao 1985). We examined the plastic crystalline state
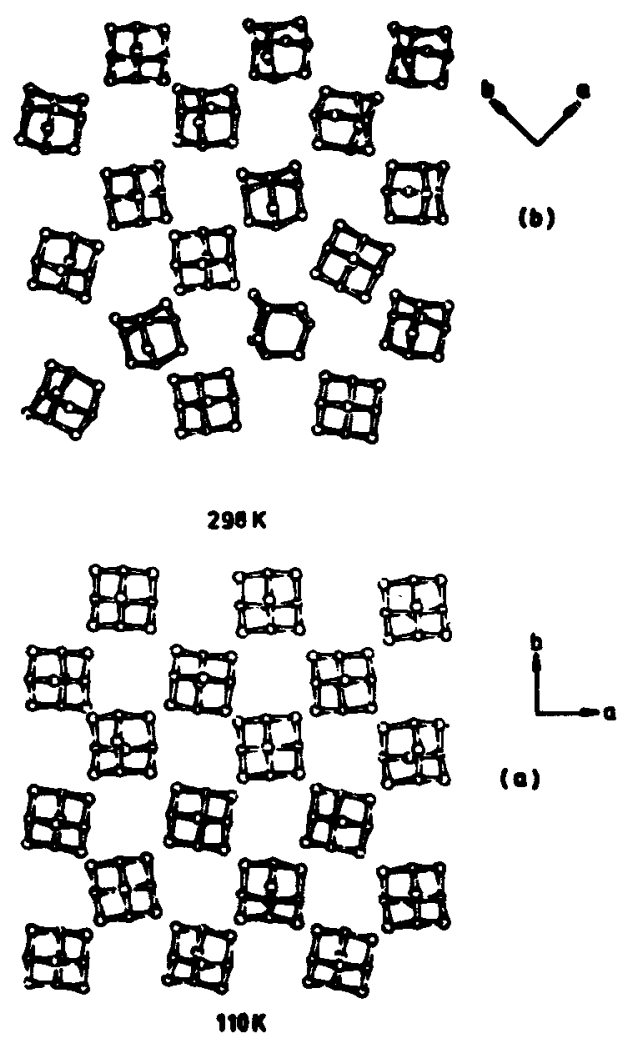

Figure 6. Computer simulation of orientationally ordered (crystalline) and disordered (plastically crystalline) phases of adamantane (Yashonath and Rao 1986). 
(figure 6), orientational glassy state, effect of vitrification of liquids and so on (Rao and Yashonath 1987; Chakrabarti et al 1992). I now work on such problems occasionally; for example, we have recently studied the orientationally disordered state of $\mathrm{C}_{60}$ (Chakrabarti et al 1992, 1993a) and also the nature of the noble gas clathrates of quinol (Santikary et al 1992). We have examined the nature of disorder in liquids compared to glasses (Chakrabarti et al 1993b) and are studying the phase transitions of biphenyl involving changes in molecular conformation.

\section{Cambridge experience}

In 1983, I was invited to be Jawaharlal Nehru Professor in Cambridge University and this was a wonderful opportunity to carry out work in a variety of areas of solid state chemistry in collaboration with Prof. J M Thomas (now Sir John Meurig Thomas) and others. The friendship between Prof. Thomas and myself which started many years ago when he was in Aberystwyth has been enduring and we have continued to collaborate over the years. A number of my students have worked with him as postdoctoral fellows. During my stay in Cambridge, I worked on the use of electron energy loss spectroscopy in conjunction with HREM for the analysis of electronic structure of oxide materials (Rao et al 1984c, d) and employed high resolution electron microscopy for the study of structural problems (see for example, Rao 1985a, Rao and Thomas 1985). During this period, I started writing the book entitled 'New directions in solid state chemistry' with J Gopalakrishnan (Rao and Gopalakrishnan 1986). This book has been a trend setter and has come in paperback edition.

\section{Catalysts}

My interest in catalysts which was kindled when I was a fresh graduate student in 1953 never left me. I very much wanted to come back to this area and do some work on the structure of catalysts to understand the nature of the active species on the surfaces of supported catalysts. In order to do this, we had to establish facilities to study catalysts in "active" or under in situ conditions of the reaction. We therefore built cells for in situ X-ray diffraction and Mössbauer spectroscopy. We acquired a Rigaku EXAFS spectrometer which we modified and improved to carry out variable temperature measurements with an in situ cell (Sankar et al 1989). Making use of EXAFS combined with XRD, Mössbauer and other measurements, the nature of metal-support interaction and of a variety of bimetallic catalysts such as $\mathrm{NiCu}$, $\mathrm{NiFe}$ and $\mathrm{RuFe} / \mathrm{Al}_{2} \mathrm{O}_{3}$ have been investigated by Sankar, Kulkarni and Kannan. Such studies have revealed unusual structural and magnetic properties of these catalysts. For example, in the $\mathrm{NiFe}$ catalysts, we can have iron in the $f c c$ and $\mathrm{Ni}$ in the bcc structure. Furthermore, the active compositions are in the form of superparamagnetic particles (Rao et al 1992a). We have carried out considerable work on the active species (Co/Ni-Mo-S) in hydrodesulphurization catalysts (figure 7). A study of methanol synthesis catalysts has shown the unusual nature of the copper species on the surface (Arunarkavalli et al 1993). We have also studied catalysts simulated in an electron spectrometer (Ranga Rao and Rao 1990). Some of these studies have been summarized in the Proceedings of the Trieste workshops on catalyst design (Graziani and Rao 1991, 1993). We have recently examined gas-sensing characteristics 


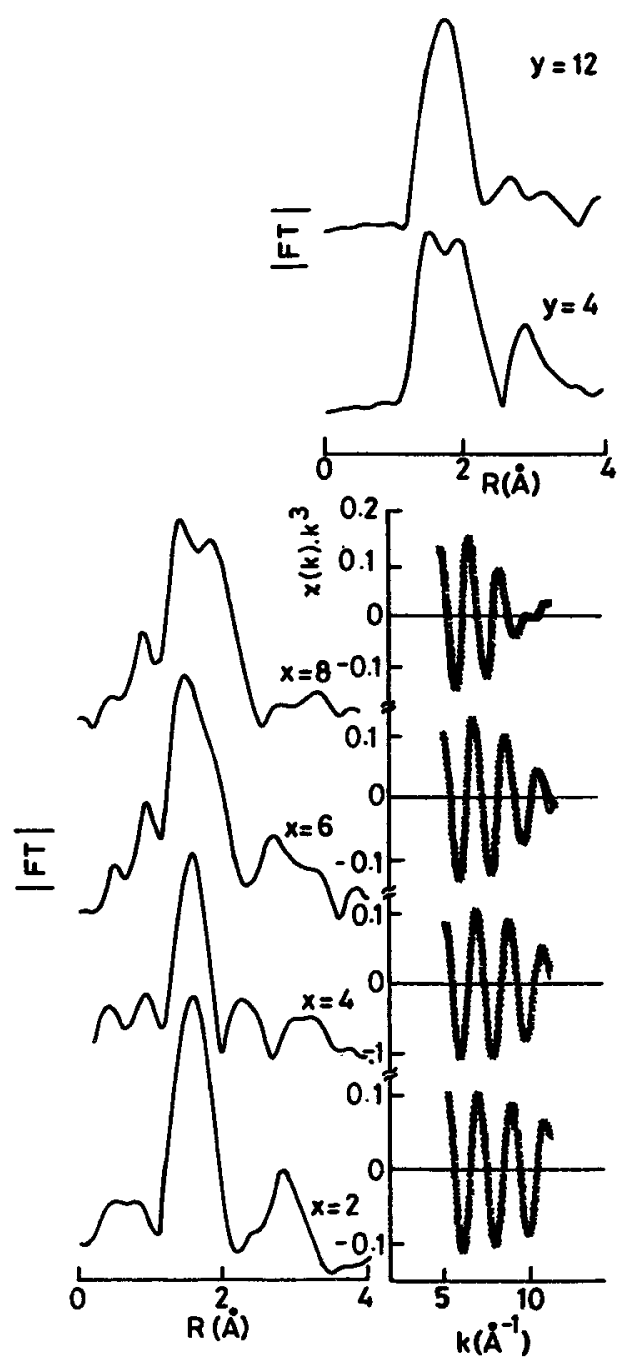

Figure 7. Fourier-transforms of the Co K-EXAFS of sulfided $x \% \mathrm{Co}-12 \% \mathrm{Mo} / \gamma-\mathrm{Al}_{2} \mathrm{O}_{3}$ $(x=2,4,6$ and 6$)$ catalysts. The best fits obtained in the curve-fitting of the inversetransformed data are also shown. The inset shown in the Fourier-transforms of Ni K-EXAFS of sulfided $2 \% \mathrm{Ni}-y \% \mathrm{Mo} / \gamma-\mathrm{Al}_{2} \mathrm{O}_{3}(y=4$ and 12) (Kulkarni and Rao 1991).

of catalytic oxides. This area could be pursued only because a good student with interest in such a problem came along to do a $\mathrm{Ph} \mathrm{D}$. degree in materials science with me (see for example, Raju and Rao 1991a, b).

\section{Synthesis}

Around 1980, it occurred to me that there was need for greater effort in the synthesis of solid materials, not only to find novel ways of making known solids, but also to prepare new, novel metastable solids by unusual chemical routes (Rao and Gopalakrishnan 1987; Rao 1993c, 1994). Some effort was soon started in this direction with the explora- 
tion of the precursor method. For example, we have employed carbonate precursors to prepare a variety of complex metal oxides. This method made use of the principle that many carbonates have the same structure as calcite and readily form solid solutions (Vidyasagar et al 1984). Such solid solutions, when decomposed, would give oxides which would be precursors for synthesizing complex oxide systems. In precursors, the diffusion distances are very small since all the relevant ions are a few Angstroms apart. A precursor was found for the synthesis of Chevrel phases. Other efforts included the synthesis of $\mathrm{MoO}_{3}$ in the metastable cubic phase rather than in the layered structure by the topochemical dehydration of the hydrate and the topochemical reduction of perovskite oxides (Rao et al 1986). Since then, activity in this direction has enhanced and we now have a significant synthetic programme in the laboratory, including the combustion method, electrochemical oxidation, alkali flux method, intercalation etc. I have just written a monograph on the synthesis of inorganic materials (Rao 1994). The first paragraph in the preface of this book may be of interest:

"Chemical methods of synthesis play a crucial role in designing and discovering novel materials, specially metastable ones which cannot be prepared otherwise. They also provide better and less cumbersome methods of preparing known materials. The tendency now a days is to avoid bruteforce methods and instead employ methods involving mild reaction conditions. Soft chemistry routes are indeed becoming popular and will undoubtedly be pursued with great vigour in the future. In view of the increasing importance being attached to materials synthesis, it was considered appropriate to outline the chemical methods of synthesis of inorganic materials in a small monograph and hence this effort."

\section{Warm superconductors}

Late in 1986 the solid state community received the big news of the discovery of a high temperature oxide superconductor (Bednorz and Müller 1986). For those working on oxides, superconductivity was not new. However, for me it was a great experience because the material that was found to be superconducting with a $T_{c}$ of $\sim 30 \mathrm{~K}$ was based on the cuprate on which I had worked on in the $1970 \mathrm{~s}$, namely, $\mathrm{La}_{2} \mathrm{CuO}_{4}$ (figure 8). In January 1987, we started working on cuprates and other materials for potential high-temperature superconductivity. In February 1987, we decided to look for an yttrium cuprate in the $\mathrm{Y}-\mathrm{Ba}-\mathrm{Cu}-\mathrm{O}$ system as a candidate for high $T_{c}$ superconductivity. Wu et al announced a yttrium cuprate with superconductivity above liquid nitrogen temperature around March 1987. Our strategy to prepare such a material was different. Wu et al obtained a mixture of a black and a green compound in their effort to make a yttrium cuprate doped with Ba. The black compound was superconducting $\left(T_{c} \sim 90 \mathrm{~K}\right)$, but they did not know its composition or structure. Since we knew that $\mathrm{Y}_{2} \mathrm{CuO}_{4}$ could not be made, Ganguly started examining the $\mathrm{Y}_{3-x} \mathrm{Ba}_{3+x} \mathrm{Cu}_{6} \mathrm{O}_{14}$ system. We obtained $90 \mathrm{~K}$ superconductivity in the $x=1$ composition corresponding to $\mathrm{YBa}_{2} \mathrm{Cu}_{3} \mathrm{O}_{7}$ (Rao et al 1987). When we discovered $90 \mathrm{~K}$ superconductivity, we knew the composition and the approximate structure of the cuprate.

We worked on a variety of cuprates such as $\mathrm{Tl}_{2}(\mathrm{Ca}, \mathrm{Ba})_{n+1} \mathrm{Cu}_{n} \mathrm{O}_{2 n+4}, \mathrm{Bi}_{2}(\mathrm{Ca}$, $\mathrm{Sr})_{n+1} \mathrm{Cu}_{n} \mathrm{O}_{2 n+4}$ and $\mathrm{Tl}(\mathrm{Ca}, \mathrm{Ba})_{n+1} \mathrm{Cu}_{n} \mathrm{O}_{2 n+3}$, but unfortunately the area was so 

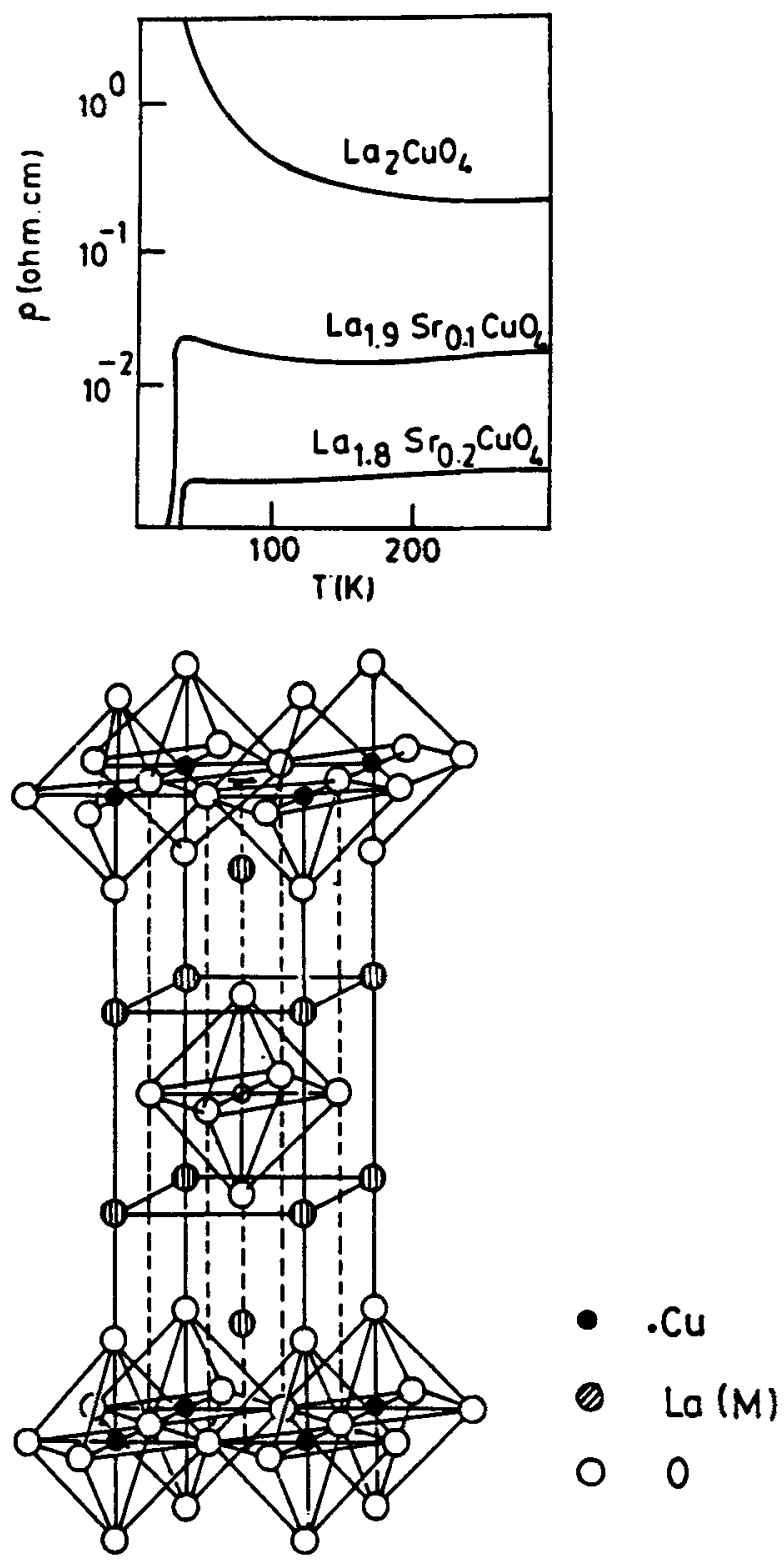

Figure 8. Structure of $\mathrm{La}_{2} \mathrm{CuO}_{4}$ or $\mathrm{La}_{2-x} \mathrm{M}_{x} \mathrm{CuO}_{4}(\mathrm{M}=\mathrm{Sr}$, Ba). Inset shows the superconducting transition in $\mathrm{La}_{1 \cdot 8} \mathrm{Sr}_{0 \cdot 2} \mathrm{CuO}_{4}$.

highly competitive and overcrowded that it has been difficult to get real credit for much of the work, even though we did the work independently. It was difficult to compete with laboratories with better facilities and better manpower. All I had were 2 or 3 Ph.D. students. In spite of these limitations, we could make some novel contributions to this area (Rao 1991a). These include, the first observation of non-resonant microwave absorption in high $T_{c}$ cuprates (Bhat et al 1987), metastability of $\mathrm{YBa}_{2} \mathrm{Cu}_{3} \mathrm{O}_{7-\delta}$ (in the $60 \mathrm{~K}$ regime, $\delta=0 \cdot 3-0 \cdot 4$ ) and its transformation to a novel type of $\mathrm{YBa}_{2} \mathrm{Cu}_{4} \mathrm{O}_{8}$ 


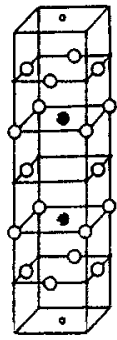

123

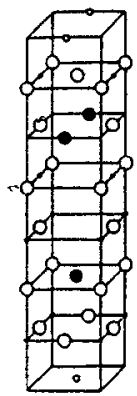

$124_{\mathrm{A}}$

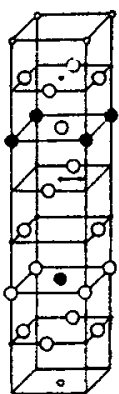

$124 \mathrm{I}$

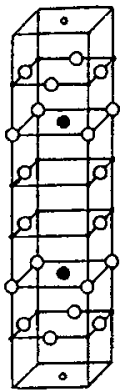

$124 p$

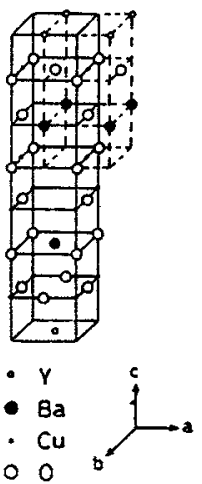

$0 \mathrm{O}$

Figure 9. Unit cells of $\mathrm{YBa}_{2} \mathrm{Cu}_{3} \mathrm{O}_{7}$ (123) and of the A-, I- and P-centred forms of $\mathrm{YBa}_{2} \mathrm{Cu}_{4} \mathrm{O}_{8}$ (124). Inset shows the shear mechanism in the A-I transformation (Nagarajan and Rao 1993).

(figure 9), the importance of $\mathrm{Cu}-\mathrm{O}$ charge transfer energy in relation to the superconductivity of cuprates (Santra et al 1991), nature of charge carriers (Sarma and Rao 1989), optimization of hole concentration in cuprates (see for example, Vijayaraghavan et al 1991), relation between $T_{c}$ and hole concentration (Rao et al 1991a) etc. On the synthetic front, we have made some contributions which we can consider to be Bangalore brand (Rao et al 1993b). For example we could make a series of superconductors in the $\mathrm{Tl}-\mathrm{Ca}-\mathrm{Sr}-\mathrm{Cu}-\mathrm{O}$ system by substitution of $\mathrm{Tb}$ by $\mathrm{Pb}$ or $\mathrm{Ca}$ by a rare earth. More interestingly, a new family of superconductors of the type $\mathrm{TiSr}_{n+1} \mathrm{Cu}_{n}$ $\mathrm{O}_{2 n+3}(n=1$ and $n=2)$ wherein $\mathrm{Sr}$ is partly substituted by a rare earth or Tl by $\mathrm{Pb}$ were discovered (see for example Ganguli et al 1989; Manivannan et al 1993). Another noteworthy contribution is the synthesis of bismuth cuprate superconductors without superstructure modulation (Manivannan et al 1991). Several other new cuprates have been synthesised and characterized here, in addition to establishing new procedures for known cuprates (Rao et al 1993b). A recent addition to this list is the synthesis and characterization of oxyanion derivatives of cuprate superconductors containing $\mathrm{CO}_{3}^{2-}, \mathrm{SO}_{4}^{2-}, \mathrm{PO}_{4}^{3-}$ and $\mathrm{BO}_{3}^{3-}$ as integral parts of the oxide framework (Ayyappan et al 1993; Rao et al 1993a; Nagarajan et al 1994). Besides publishing several papers and reviews (Ramakrishnan and Rao 1989; Rao and Raveau 1989; Rao 1991a; Rao et al 1993b) and editing books (Rao 1988, 1991b) on the subject, Prof. T V Ramakrishnan and I have written a small education monograph on superconductivity (Ramakrishnan and Rao 1992). While it is true that solid state chemistry has contributed much to the understanding of oxide superconductors, it is also true that high $T_{c}$ superconductivity gave a big boost to solid state chemistry.

\section{Metal clusters}

For sometime I have been interested in the study of metal clusters. The main motivation to study metal clusters (deposited on solid substrates) was to explore whether there would be characteristic changes in properties such as metallicity and chemical reactivity when we go from the atomic state to the bulk metal. Metal clusters occur 
in a regime between that of atoms and that of the bulk metal. One of the problems we have tackled (since 1990) is to understand how the metallicity varies as the size of the clusters decreases. By employing high energy spectroscopies (X-ray and UV photoelectron spectroscopy, Bremstrahlung isochromat spectroscopy etc) along with high resolution microscopies (HREM and scanning tunnelling microscopy, see figure 10), we have been able to show how non-metallicity manifests itself when the cluster diameter is $1 \mathrm{~nm}$ or less (Vijayakrishnan et al 1992; Rao et al 1993d). Such small clusters show a conductance gap (due to nonmetallicity) as revealed by tunnelling measurements. We have studied the variation of chemical reactivity with cluster size (Rao et al 1992b). We have made bimetallic clusters and compared their properties with those of bimetallic overlayers and alloys. Another aspect of interest is to examine the mechanism of growth of metal clusters in solution. Since we can make small clusters $(\lesssim 1 \mathrm{~nm})$ in solution by employing special reducing agents, this problem can be studied effectively.
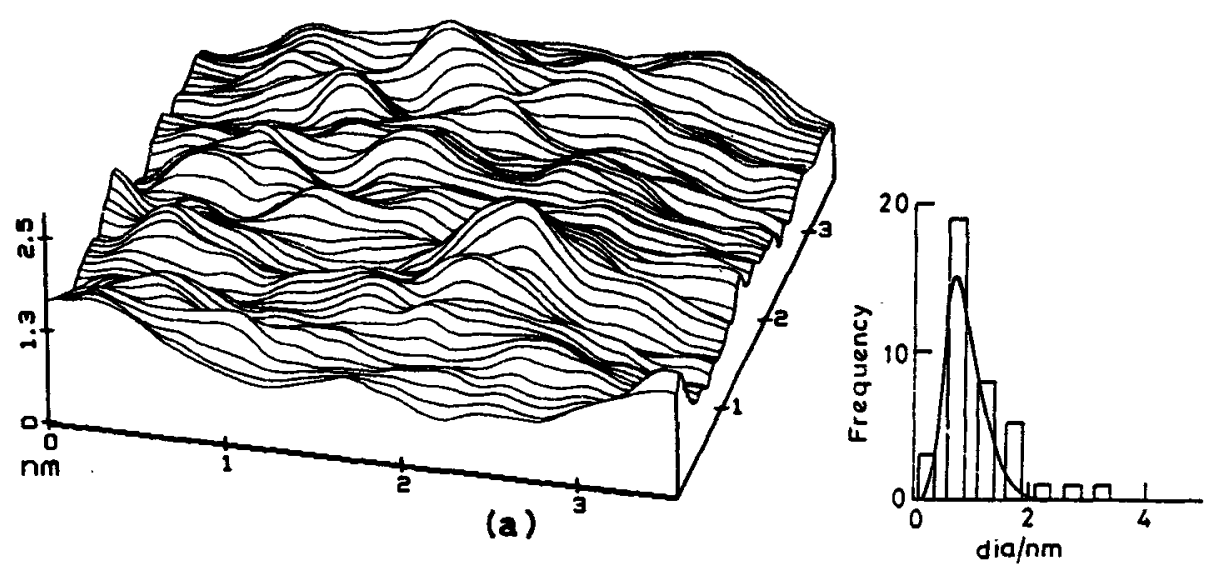

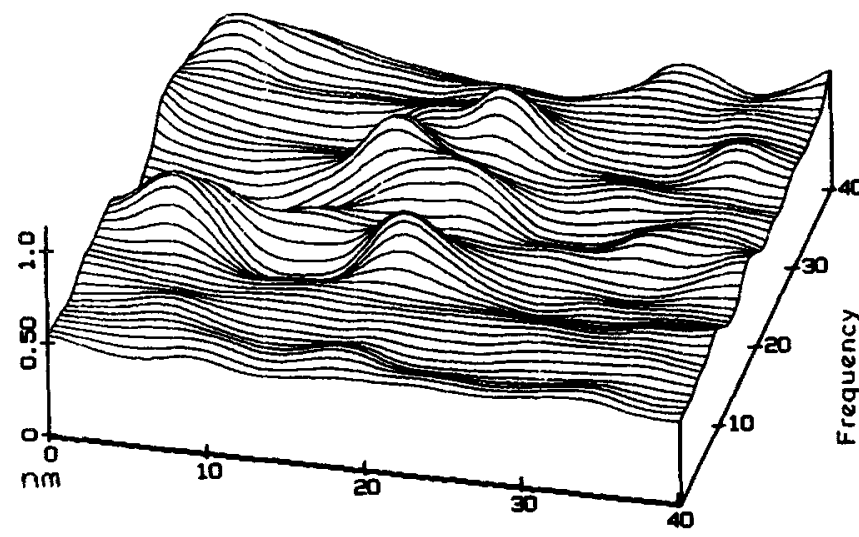

(b)

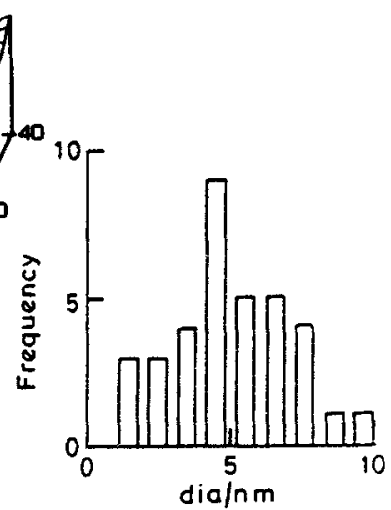

Figure 10. STM contour plots of Au clusters (with histograms of cluster sizes) prepared by (a) $1 \mathrm{~nm}$ cluster by THPC reduction and (b) $5 \mathrm{~nm}$ clusters by alkalide reduction (Kulkarni et al 1993a). 


\section{Fullerenes}

As if excitement with superconductivity and metal clusters was not enough, around 1991, the laboratory preparation of the fullerenes $C_{60}$ and $C_{70}$ was announced. I did not want to get into this area since I was already more than busy with my work on oxides, superconductivity, synthesis of solids, metal clusters and so on. However, when I talked to a number of younger people in this Institute and elsewhere in the country to get into fullerene research, I did not get any enthusiastic response. It was then that I decided to start work in this area with Pradeep who rightaway fabricated a couple of units for the arc evaporation of graphite (Pradeep and Rao 1991). We have investigated a variety of problems on fullerenes starting with the synthesis, purification, spectroscopy and solid state properties. For example, we discovered an easy way of making $C_{60}$ and $C_{70}$ by a simple filtration technique using silica-charcoal as absorbent. We have studied the electronic spectroscopy of $\mathrm{C}_{60}$ and $\mathrm{C}_{70}$ (figure 11) and also the interaction of these fullerenes with amines to form complexes in the ground and excited states (exciplexes). We established the formation of exciplexes between aromatic amines and fullerenes and the formation of weak complexes in the ground state (Seshadri et al 1993). $\mathrm{C}_{60}$ and $\mathrm{C}_{70}$ also interact weakly with aromatic molecules like benzene. More interesting is the solid adduct between $\mathrm{C}_{60}$ and the strong donor amine TDAE, which is soft molecular ferromagnet with the highest $T_{c}$ todate $(\sim 16 \mathrm{~K})$. We have studied $\mathrm{C}_{60}$. TDAE by employing ESR and Raman spectroscopy (see for example Muthu et al 1994). A topic that has occupied much of our
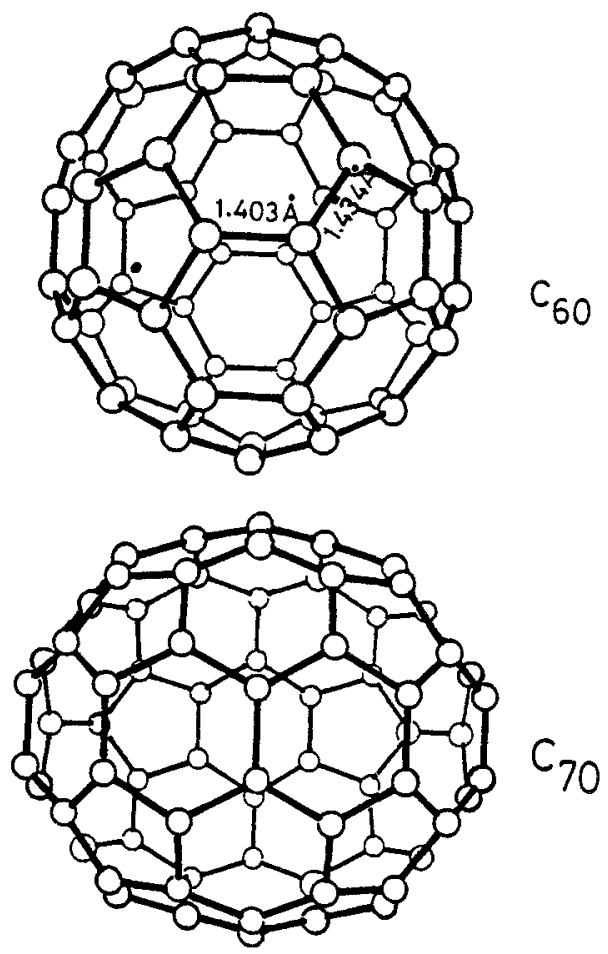

Figure 11. Structures of $\mathrm{C}_{60}$ and $\mathrm{C}_{70}$. 


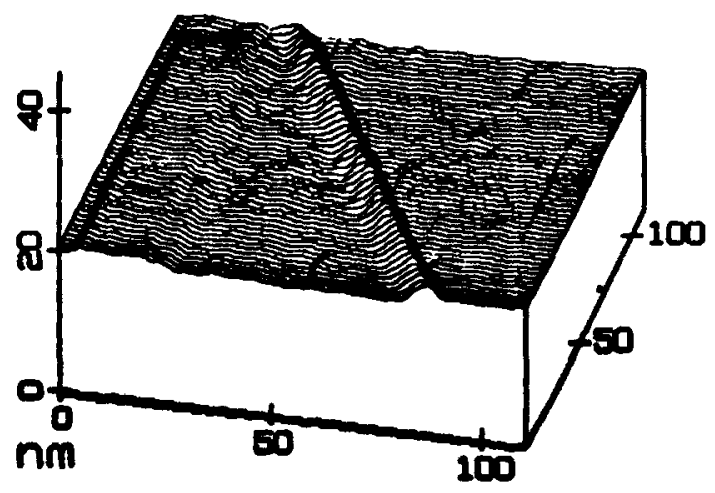

Figure 12. STM contour plot of a carbon tubule (from Aiyer and Seshadri).

attention is the study of phase transitions of $\mathrm{C}_{60}$ and $\mathrm{C}_{70}$ associated with orientational ordering (Chandrabhas et al 1992, 1993; Rao et al 1993c). We have examined the phase transitions by employing Raman spectroscopy and other techniques at ambient and high pressures. The occurrence of the orientational glassy state of $\mathrm{C}_{60}$ at low temperature is an interesting phenomenon. We have found it difficult to study the chemistry of fullerenes due to limitations in the characterization facilities.

We have started investigating the properties of carbon nanotubes (figure 12). A property of particular interest is to find out whether the nanotubes are metallic or insulating. While a single nanotube itself has a diameter of $10 \AA$, the tubules come with differing numbers of graphite sheaths. It would be interesting to open the tubules and stuff them with metals etc.

\section{Other studies}

Besides the different areas in solid state chemistry described hitherto, we have tackled other types of problems as and when the occasion arose. For example, we have studied ternary metal sulfides (Murugesan et al 1981, 1982). We have investigated metal-ceramic composites by employing Mössbauer and ESR spectroscopies and other techniques in collaboration with Prof. Rousset and his coworkers (see for example Laurent et al 1993). We have studied interesting ferrites such as $\mathrm{Fe}_{3-x} \mathrm{Mo}_{x} \mathrm{O}_{4}$ (Bouet et al 1993) and the finite-size scaling effect in $\mathrm{MnFe}_{2} \mathrm{O}_{4}$ (Kulkarni et al 1993b).

We have employed photoacoustic spectroscopy to study solids and surfaces by making use of a locally fabricated spectrometer (Rao and Ganguly 1981; Rao et al 1982; Somasundaram et al 1986). Solid state magic angle spinning NMR spectroscopy has been exploited to study several types of glasses (see for example, Prabhakar et al 1987, 1991).

Research on surface science was started in IISc, Bangalore in 1978, but I will not dwell much on it here because several of these studies deal with the interaction of molecules with solid surfaces. However, we did investigate several problems related to the electronic structures of solids, specially metal oxides (Rao et al 1979; Rao and Hegde 1981; Hegde et al 1982; Rao and Sarma 1982; Sarma et al 1982; Rao 1986a). We have studied metal oxidation (Rao et al 1980; Sarma et al 1981; Sen et al 1984), 
metal-insulator transitions, spin-state transitions (Vasudevan et al 1979), mixed valency and such phenomena by electron spectroscopic techniques.

I tried to initiate a programme on the organic solid state and even published a few papers (see for example, Guru Row et al 1983, Theocaris et al 1984), but soon decided not to continue since I had to depend heavily on the synthetic skills of students who were generally physical chemists.

\section{Epilogue}

I believe that I have elaborated sufficiently on the kind of research that I have pursued in the area of solid state chemistry for nearly four decades. I had to work on various aspects of the subject during this period, because the subject was at its infancy or was just growing. I wanted to contribute to the various facets of the subject, such as synthesis, structure, properties, reactivity, surfaces, design of new solids, and phase transitions, from India. Because of this zeal, I have ended up publishing extensively, papers in solid state chemistry alone reaching 570 . It is not that I wanted to publish more papers. I just could not help completing several investigations on different aspects and on different systems with my young students and coworkers. Because the subject was new and important, I was also committed to writing reviews periodically on certain aspects of solid state chemistry, in addition to bringing out books of value to students, teachers and practitioners.

I continue to be deeply involved in solid state chemistry research. Besides working on the synthesis, structure and properties of various types of oxides and other materials (Rao 1993a), I would like to investigate certain solids and nanomaterials by high resolution electron microscopy with $1.7 \AA$ resolution, but this requires some investment. I hope that such a facility can be established in the near future. I plan to study solid surfaces by employing vibrational electron energy loss spectroscopy as well as scanning tunnelling microscopy; this would again require new facilities. I have just initiated some work on structural phase transitions of molecular solids by employing crystallography (charge densities) and time-resolved measurements.

As far as synthesis is concerned, while it may not demand many facilities, it requires besides chemical ingenuity, dedicated, sophisticated equipment for the elucidation of structure. I expect to be able to design and synthesize some novel solids as part of the on-going activity. A recent innovation that we are pursuing in synthesis is the use of nebulized spray pyrolysis (figure 13). In this technique, we take the organic derivatives of all the relevant cations in solution in an organic solvent and nebulize the solution by using a transducer. By using appropriate substrates, we can deposit films of a variety of materials (a few Angstroms to microns), including metals, dielectrics, superconductors, magnetic materials and so on. This gives us the possibility of investigating films of interesting materials (e.g. $\mathrm{La}_{4} \mathrm{Ni}_{3} \mathrm{O}_{10}$ ) as well as overlayers of different types of materials (e.g. dielectrics and superconductors). Nebulized spray pyrolysis is a poor man's MOCVD.

I plan to enlarge the scope of our work on carbon clusters (fullerenes) to study nanostructures of carbon, including not only carbon nanotubes but also other structures such as carbon onions and onions encaptulating metal or metal carbide species. I would like to examine carbon nanostructures that can be produced by the pyrolysis of hydrocarbons. Conversion of carbon to diamond in the solid state is 


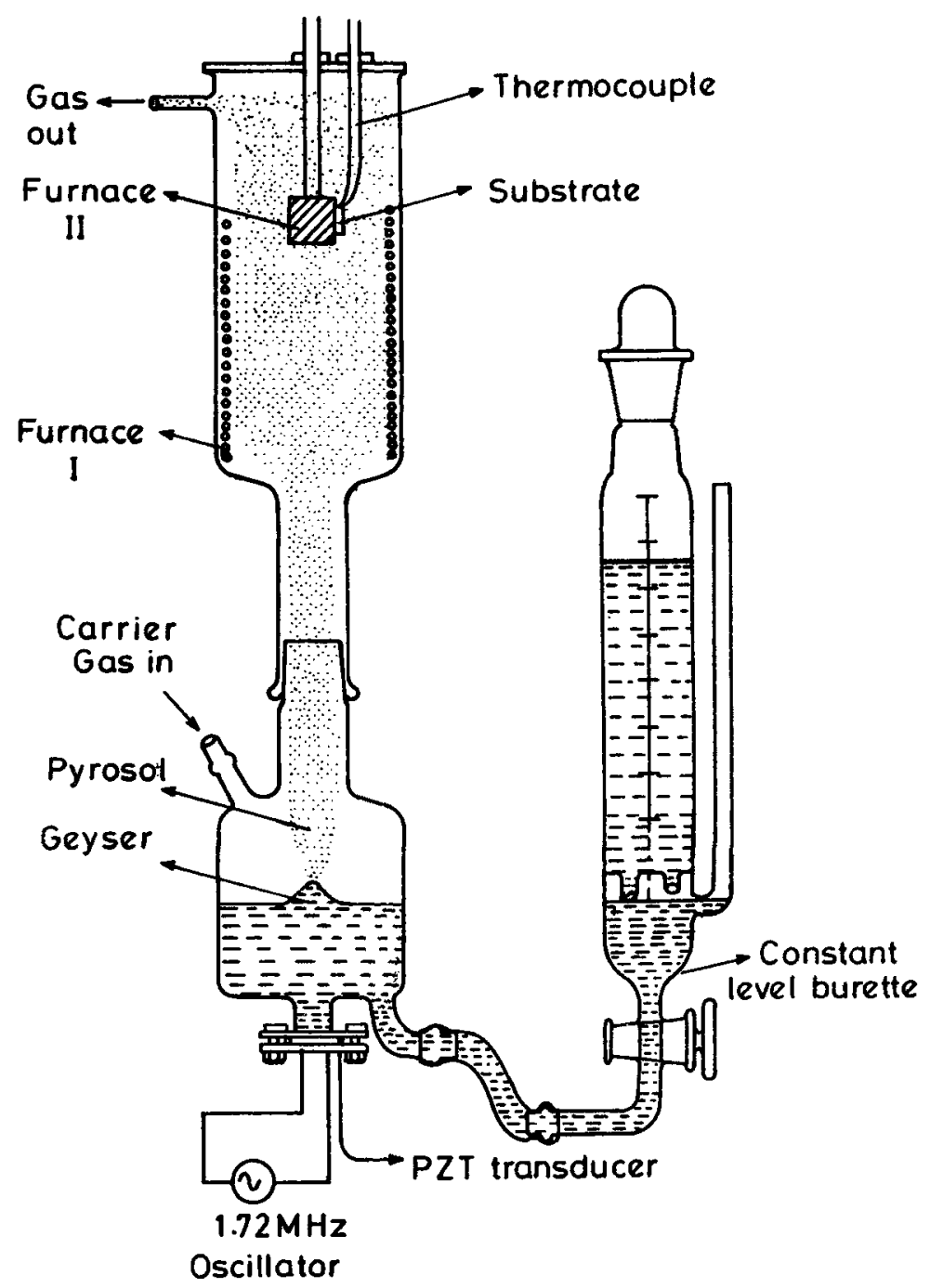

Figure 13. Apparatus for nebulized spray pyrolysis (from Raju).

another interesting problem. I am also hoping to work on the conversion of inorganic carbonates to hydrocarbons since somewhere in the middle of the 21 st century the only source of carbon would be carbonaceous rocks.

I have been inspired by some great men of science in whatever I have been doing. I could not resist the urge to publish because I have always been inspired by Faraday who said that the main activity of scientists is to "work, finish and publish". I have worked on a large variety of problems because I have been inspired by $\mathbf{G} \mathrm{N}$ Lewis who said that "physical chemistry was anything that was interesting". I had to often take up newer problems or newer aspects of a problem to suit the facilities as well as the interests and abilities of my students. I have had immense happiness in working with young coworkers. I also gave up working in certain areas when my former students started contributing to them in a major way. In this respect, I have been 
inspired by Lord Rutherford who took much more pride in the work of his students than what he did himself. I will feel more than rewarded if people feel that my coworkers and I have contributed to the growth of various facets of solid state chemistry in the last few decades or still better if they consider that we have been partly responsible for the growth of the subject.

\section{Acknowledgements}

I owe much to my teachers during my graduate and post-doctoral studies, Professors E Lieber, R L Livingston, Herbert C Brown and K S Pitzer. I would like to record my deep sense of gratitude to (late) Prof. J S Anderson, F.R.S. and to Prof. Sir Nevil Mott, F.R.S. who have been great sources of encouragement and to Professors J M Honig, J B Goodenough and Sir John Meurig Thomas, F.R.S., for their longstanding friendship and collaboration. I would like to specially acknowledge the enormous boost to my morale that $I$ have received over the years from my dear friend John Thomas. In recent years, I have had the pleasure of collaborating closely with Professors B Raveau, P P Edwards and A Rousset.

In the past 1.5 years I have been associated with the University of Wales, Cardiff, as an honorary professor and have been able to start some research work there, thanks to Prof. Wyn Roberts.

I have had the pleasure of collaborating with many colleagues, some of whom were my former pupils and I would like to specially acknowledge the enthusiastic collaboration I have had with Professors P Ganguly, J Gopalakrishnan, T N Guru Row, M S Hedge, S Ramasesha, K J Rao, D D Sarma, S Yashonath and A M Umarji. Of the physicists with whom I have had close collaboration, special thanks are due to Professors S V Bhat, V G Bhide, N Kumar, T V Ramakrishnan, A K Ray Chaudhuri, R M Singru and A K Sood.

I would like to express my deep sense of gratitude to my Ph.D. students, postdoctoral Fellows and other coworkers for their unstinted support, loyalty and enthusiastic collaboration. I list below my young coworkers in various categories. Those who received Ph.D. degrees in solid state chemistry and related areas: Drs $\mathbf{S} \mathbf{R}$ Yoganarasimhan, R L N Sastry, P N Mehrotra, K J Rao, K C Patil, G V Subba Rao, S Ramdas, M Natarajan, A K Shukla, G Rama Rao, S Ramasesha, D Bahadur, Om Parkash, S Vasudevan, M K Uppal, S Kollali, P K Basu, W H Madhusudan, D D Sarma, S Ganguly, P V Kamath, R Murugesan, R Parthasarathy, A Srinivasan, S Yashonath, P Sen, K Vidyasagar, G Sankar, K Prabhakaran, R A Mohan Ram, A K Ganguli, M K Rajumon, G Ranga Rao, L Ganapathi, S Prabhakar, G N Subbanna, T Pradeep, R Vijayaraghavan, $G U$ Kulkarni, V Varma, $R$ Nagarajan and $P$ Somasundaram. Those who have worked with me during their graduate studies, though not formally my Ph.D. students: Drs R E Loehman, K P Singh, V Jadhao, G Thornton, D J Buttrey, A Ramanan, N Vasanthacharya, K K Singh, K Sreedhar, K S Nanjundaswamy, H N Vasan, Ch. Laurent and L Bouet. Those who have carried out post-doctoral work with me: Drs G V Chandrashekhar, B Prakash, M S Tomar, P Ganguly, B Viswanathan, M S Hegde, P R Sarode, J R Fernandes, G R Desiraju, Seetha Bharathi, K Jagannathan, N R Jagannathan, R Bhattcharya and M Verelst. Those who did their Master's degree thesis: Dr D K Agarwal, Messrs V Jayaram and K R Kannan. Those who are presently carrying out their Ph.D. work in solid 
state chemistry: Messrs V Vijayakrishnan, $\mathbf{N}$ Manivannan, N Rangavittal, R Mahesh, A K Santra, R Seshadri, A Raju, A Govindaraj, H N Aiyer and S Ayyappan, Ms A Chakrabarti and Ms T Arunarkavalli.

I acknowledge the support received from the Department of Science and Technology, CSIR, University Grants Commission, US National Science Foundation, European Economic Community and the Indo-French Centre for Advanced Research for my research work in solid state chemistry.

\section{References}

Arunarkavalli T, Kulkarni G U and Rao C N R 1993 Catal. Lett. 20259

Ayyappan S, Manivannan V and Rao C N R 1993 Solid State Commun. 87551

Bahadur D, Kollali S and Rao C N R 1979 J. Phys. Chem. Solids 40981

Bednorz G and Müller K A 1986 Z. Phys. B64 189

Beniere F, Catlow C R A, Shukla A K and Rao C N R 1977 J. Phys. Chem. Solids 38521

Bhat S N and Rao C N R 1969 Canadian J. Chem. 473899

Bhat S N, Chandrashekhar G V and Rao C N R 1967 Inorg. Nucl. Chem. Lett. 3409

Bhat S V, Ganguli P, Ramakrishnan T V and Rao C N R 1987 J. Phys. C20 L559

Bhide V G, Rajoria G S, Rao G R and Rao C N R 1972 Phys. Rev. B6 1021

Bouet L, Tailhaides Ph, Rousset A, Kannan K R, Verelst M, Kulkarni G U and Rao C N R 1993 J. Solid State Chem. 102414

Buttrey D, Ganguly P, Honig J M and Rao C N R 1988 J. Solid State Chem. 74233

Chakrabarti A, Yashonath S and Rao C N R 1992 J. Phys. Chem. 966762

Chakrabarti A, Yashonath S and Rao C N R 1993a Chem. Phys. Lett. (in print)

Chakrabarti A, Yashonath S and Rao C N R 1993b Mol. Phys. (in print)

Chandrabhas N, Shashikala M N, Muthu D V S, Sood A K and Rao C N R 1992 Chem. Phys. Lett. 197319

Chandrabhas N, Jayaram K, Muthu DV S, Sood A K, Seshadri R and Rao C N R 1993 Phys. Rev. B47 10963

Chandrashekhar G V, Mehrotra P N, Subba Rao G V, Subbarao E C and Rao C N R 1967 Trans. Faraday Soc. 631295

Cheetham A K and Rao C N R 1976 Acta Crystallogr. B32 1579

Czanderna A, Rao C N R and Honig J M 1958 Trans. Faraday Soc. 541069

Edwards P P and Rao C N R (eds) 1985 The metallic and non-metallic states of matter (London: Taylor and Francis)

Gai P L, Rao C N R and Anderson J S 1975 J. Phys. D 8 L157

Gai P L, Jacobson A J and Rao C N R 1976 Inorg. Chem. 15480

Ganguli A K, Manivannan V, Sood A K and Rao C N R 1989. Appl. Phys. Lett. 552664

Ganguly P and Rao C N R 1973 Mater. Res. Bull. 8405

Ganguly P, Om Parkash and Rao C N R 1976 Phys. Status Solidi A36 669

Ganguly P, Kollali S and Rao C N R 1980 Magn. Lett. 1107

Ganguly P and Rao C N R 1984 J. Solid State Chem. 53193

Ganguly P, Vasantacharya N Y, Rao C N R and Edwards P P 1984 J. Solid State Chem. 53140

Goodenough J B and Rao C N R 1983 Curr. Sci. 52391

Graziani M and Rao C N R (eds) 1991 Advances in catalyst design (Singapore: World Scientific)

Graziani M and Rao C N R (eds) 1993 Advances in catalyst design (Singapore: World Scientific)

Guru Row T N, Swamy H R, Acharya K R, Ramamurthy V, Venkatesan K and Rao C N R 1983 Tet, Lett. 243265

Hegde M S, Srinivasan A, Sarma D D and Rao C N R 1982 J. Electron Spectrosc. Rel. Phen. 25231

Honig J M and Rao C N R (eds) 1981 Preparation and characterization of materials (New York: Academic Press)

Hutchison J L, Anderson J S and Rao C N R 1976 Proc. R. Soc. London A355 301

Jadhao V G, Singru R M, Bahadur D and Rao C N R 1976 J. Phys. Chem. Solids 37113

Kulkarni G U and Rao C N R 1991 Catal. Lett. 9427

Kulkarni G U, Aiyer H N, Vijayakrishnan V, Arunarkavalli T and Rao C N R 1993a JCS Chem. Commun. 1545 
Kulkarni G U, Kannan K R, Arunarkavalli T and Rao C N R 1993b Phys. Rev. B (in print) Laurent Ch, Rousset A, Verelst M, Kannan K R, Raju A R and Rao C N R 1993 J. Mater. Chem. 3513 Madhusudan W H, Ganguly P, Jagannathan K and Rao C N R 1980 J. Chem. Soc. Dalton 1397 Manivannan V, Gopalakrishnan J and Rao C N R 1991 Phys. Rev. B43 8686

Manivannan V, Rangavittal N, Gopalakrishnan J and Rao C N R 1993 Physica C208 253

Mohan Ram R A, Singh K K, Ganguly P and Rao C N R 1983 Mater. Res. Bull. 18703

Murugesan T, Ramesh S, Gopalakrishnan J and Rao C N R 1981 J. Solid State Chem. 38165

Murugesan T, Ramesh S, Gopalakrishnan J and Rao C N R 1982 J. Solid State Chem. 44119

Muthu D V S, Shashikala M N, Sood A K, Seshadri R and Rao C N R 1994 Chem. Phys. Lett. (to be published)

Nagarajan R and Rao C N R 1993 J. Solid State Chem. 103533

Nagarajan R, Ayyappan S and Rao C N R 1994 Physica C (to be published)

Om Parkash and Rao C N R 1977 Philos. Mag. 351111

Parthasarathy R, Rao K J and Rao C N R 1983 Chem. Soc. Rev. 12361

Pitzer K S, Gerkin R E, Gregor L V and Rao C N R 1961 Pure Appl. Chem. 2211

Prabhakar S, Rao K J and Rao C N R 1987 Chem. Phys. Lett. 13996

Prabhakar S, Rao K J and Rao C N R 1991 Chem. Phys. Lett. 183176

Pradeep T and Rao C N R 1991 Mater. Res. Bull. 261101

Raju A R and Rao C N R 1991a Sensors and Activators B 3305

Raju A R and Rao C N R 1991b J. Chem. Soc. Chem. Commun. 1260

Ramakrishnan T V and Rao C N R 1989 J. Phys. Chem. 934414

Ramakrishnan T V and Rao C N R 1992 Superconductivity today (New Delhi: Wiley Eastern)

Ramanan A, Gopalakrishnan J and Rao C N R 1981 Mater. Res. Bull. 16163

Ramanan A, Gopalakrishnan J and Rao C N R 1985 J. Solid State Chem. 60376

Ramasesha S, Ramakrishnan T V and Rao C N R 1979 J. Phys. C12 1307

Ramdas S, Patil K C and Rao C N R 1970 J. Chem. Soc. 64

Ramdas S, Shukla A K and Rao C N R 1973 Phys. Rev. 882975

Ramdas S and Rao C N R 1976 Cryst. Latt. Defects 6199

Ranga Rao G and Rao C N R 1990 J. Phys. Chem. 947986

Rao C N R and Gregor L V 1959 Nature (London) 1831391

Rao C N R and Pitzer K S 1960 J. Phys. Chem. 64282

Rao C N R 1961a Ultraviolet and visible spectroscopy (London: Butterworths) (First edition, several editions, reprinted and translations have appeared since)

Rao C N R 1961b Canadian J. Chem. 39498

Rao C N R, Faeth P and Yoganarasimhan S R 1961 Trans. Faraday Soc. 57504

Rao C N R 1963 Chemical applications of infrared spectroscopy (New York: Academic Press)

Rao C N R and Rao K J 1967 Prog. Solid State Chem. 4131

Rao C N R, Loehman R and Honig J M 1968 Phys. Lett. A27 271

Rao C N R and Bhat S N 1969 Inorg. Nucl. Chem. Lett. 553

Rao C N R (ed.) 1970 Modern aspects of solid state chemistry (New York: Plenum Press)

Rao C N R and Subba Rao G V 1970 Phys. Status Solidi 1a 597

Rao C N R, Ramdas S, Loehman R and Honig J M 1971 J. Solid State Chem. 383

Rao C N R, Rao G R and Subba Rao G V 1973 J. Solid State Chem. 6340

Rao C N R (ed.) 1974 Solid state chemistry (New York: Marcel Dekker)

Rao C N R and Subba Rao G V 1974 Transition metal oxides NSRDS-NBS Monograph 49, (Washington, DC: National Bureau of Standards)

Rao C N R and Mott N F 1975 Philos. Mag. 321277

Rao C N R, Om Parkash and Bahadur D 1977 J. Solid State Chem. 22353

Rao C N R and Rao K J 1978 Phase transitions in solids (New York: McGraw Hill)

Rao C N R, Sarma D D, Vasudevan S and Hegde M S 1979 Proc. R. Soc. London A367 239

Rao C N R, Sarma D D and Hegde M S 1980 Proc. R. Soc. London A370 269

Rao C N R and Ganguly P 1981 Proc. Indian Acad. Sci. 90153

Rao C N R and Hegde M S 1981 in Preparation and characterization of materials (eds) J M Honig and C N R Rao (New York: Academic Press)

Rao C N R, Ganguly P and Jagannathan K 1982 J. Mol. Struct. 79173

Rao C N R and Sarma D D 1982 J. Solid State Chem. 4514

Rao C N R 1984 Acc. Chem. Res. 1783 
Rao C N R, Buttrey D, Ganguly P and Honig J M 1984a J. Solid State Chem. 51266

Rao C N R, Gopalakrishnan J and Vidyasagar K 1984b Indian J. Chem. 23A 265

Rao C N R, Sparrow T G, Thomas J M and Williams B G 1984c J. Chem. Soc. Chem. Commun. 1238

Rao C N R, Thomas J M, Williams B G and Sparrow T G 1984d J. Phys. Chem. 885769

Rao C N R 1985a Bull. Mater. Sci. 7155

Rao C N R 1985b Int. Rev. Phys. Chem. 419

Rao CN R and Ganguly P 1985 in Localization and metal-insulator transitions (eds) D Adler and H Fritsche (New York: Plenum Press)

Rao C N R and Thomas J M 1985 Acc. Chem. Res. 18113

Rao C N R 1986a Philos. Trans. R. Soc. London A317 37

Rao C N R 1986b Proc. Indian Nat. Sci. Acad. A52 1

Rao C N R and Gopalakrishnan J 1986 New directions in solid state chemistry (Cambridge, UK: Cambridge University Press)

Rao C N R, Gopalakrishnan J, Vidyasagar K, Ganguli A K and Ramanan A 1986 J. Mater. Res. 1280 Rao C N R and Gopalakrishnan J 1987 Acc. Chem. Res. 20228

Rao C N R, Ganguly P, Raychaudhuri A K, Mohan Ram R A and Sreedhar K 1987 Nature (London) 326856

Rao C N R and Yashonath S 1987 J. Solid State Chem. 8819

Rao C N R (ed.) 1988 Chemistry of oxide superconductors (Oxford: Blackwell)

Rao C N R, Ganguly P, Singh K K and Mohan Ram R A 1988 J. Solid State Chem. 7214

Rao C N R 1989 Ann. Rev. Phys. Chem. 40291

Rao C N R and Raveau B 1989 Acc. Chem. Res. 22106

Rao C N R 1991a Philos. Trans. R. Soc. London 336595

Rao C N R (ed.) 1991b Chemistry of high temperature superconductors (Singapore: World Scientific)

Rao C N R, Gopalakrishnan J, Santra A K and Manivannan V 1991a Physica C174 11

Rao C N R, Kulkarni G U, Kannan K R and Chaturvedi S 1992a J. Phys. Chem. 967379

Rao C N R, Vijayakrishnan V, Santra A K and Prins M S W 1992b Angew. Chem. (Int. Ed.) 311064

Rao C N R (ed.) 1993a Chemistry of advanced materials (Oxford: Blackwell)

Rao C N R, Ganguly P, Singh K K and Mohan Ram R A 1988 J. Solid State Chem. 7214

Rao C N R 1993b J. Mol. Struct. 292229

Rao C N R 1993c Mater. Sci. Engg. B18 1

Rao C N R, Nagarajan R, Ayyappan S, Mahesh R and Subbanna G N 1993a Solid State Commun. 88757

Rao C N R, Nagarajan R and Vijayaraghavan R 1993b Supercond. Sci. Tech. 61

Rao C N R, Seshadri R and Sood A K 1993c Proc. IUMRS Meeting, Tokyo (Amsterdam: Elsevier)

Rao C N R, Vijayakrishnan V, Aiyer H K and Kulkarni G U 1993d J. Phys. Chem. 9711157

Rao C N R 1994 Chemical approaches to the synthesis of inorganic materials (New York: John Wiley) (to be published)

Rao K J and Rao C N R 1966 J. Mater. Sci. 1238

Rao K J, Subba Rao G V and Rao C N R 1967 Trans. Faraday Soc. 631013 (also see ibid 197065 2497)

Rao K I and Rao C N R 1968 Phys. Status Solidi 28157

Sankar G, Kulkarni G U and Rao C N R 1989 Prog. Cryst. Growth. Characterization 1869

Santikary P, Yashonath S and Rao C N R 1992 Chem. Phys. Lett. 192390

Santra A K, Sarma D D and Rao C N R 1991 Phys. Rev. B43 5612

Sarma D D, Hegde M S and Rao C N R 1981 J. Chem. Soc. Faraday 2771509

Sarma D D, Kamath P V and Rao C N R 1982 Chem. Phys. 7371

Sarma D D and Rao C N R 1989 Synth. Metals 33131

Sastry R L N, Mehrotra P N and Rao C N R 1966 J. Inorg. Nucl. Chem. 282167

Sen P, Sarma D D, Budhani R C, Chopra K L and Rao C N R 1984 J. Phys. F14 565

Seshadri R, Rao C N R, Pal H, Mukherjee T and Mittal J P 1993 Chem. Phys. Lett. 205395

Shukla A K, Ramdas S and Rao C N R 1973a J. Solid State Chem. 8120

Shukla A K, Ramdas S and Rao C N R 1973b J. Chem. Soc. Faraday 269207

Singh K K, Ganguly P and Rao C N R 1982 Mater. Res. Bull. 17493

Somasundaram T, Ganguly P and Rao C N R 1986 J. Phys. C Solid State 192137

Subba Rao G V, Ferraro J R and Rao C N R 1970 Appl. Spectrosc. 24436

Subba Rao G V, Wanklyn B M and Rao C N R 1971 J. Phys. Chem. Solids 32345

Theocaris C, Jones W and Rao C N R 1984 J. Chem. Soc. Chem. Commun. 1291

Uppal M K, Sangster M J L and Rao C N R 1978 Philos. Mag. 38341

Uppal M K, Ramasesha S and Rao C N R 1980 Acta Crystallogr. A36 356 
Varma K B R, Subbanna G N, Guru Row T N and Rao C N R 1990 J. Mater. Res. 52718

Vasudevan S, Vasan H N and Rao C N R 1979 Chem. Phys. Lett. 65444

Verelst M, Rangavittal N and Rao C N R 1993 J. Solid State Chem. 10474

Vidyasagar K, Gopalakrishnan J and Rao C N R 1984 Inorg. Chem. 231206

Vijayaraghavan R, Rangavittal N, Grantscharova E, Guru Row T N and Rao C N R 1991 Physica C179 183

Vijayakrishnan V, Chainani A, Sarma D D and Rao C N R 1992 J. Phys. Chem. 968679

Yashonath S and Rao C N R 1985 Mol. Phys. 54245

Yashonath S and Rao C N R 1986 J. Phys. Chem. 902552

Yoganarasimhan S R and Rao C N R 1962 Trans. Faraday Soc. 581579 